\title{
ALGUNS COMENTÁRIOS SOBRE A HISTÓRIA DO CONHECIMENTO HISTÓRICO
}

\author{
Silvia Regina Ferraz Petersen
}

\begin{abstract}
RESUMO: Ce texte a pour objet d'analyser la trajectoire de la connaissance historique à partir du XIX $\mathrm{X}^{\mathrm{e}}$ siècle, quand l'histoire s'est rapprochée du domaine scientifique; il le fait en caractérisant les principales tendances théorico-méthodologiques du XX $\mathrm{X}^{\mathrm{e}}$ siècle et en signalant quels sont les débats, les progrès et les impasses qui ont marqué la production historiographique des dernières années.
\end{abstract}

PALAVRAS-CHAVE: Conhecimento histórico, Historiografia, Teoria e metodologia da história

Para que se possa entender o perfil do conhecimento histórico na atualidade, acho necessário voltar um pouco no tempo e analisar certos momentos de sua trajetória extraordinariamente rica que, no espaço de um século desloca-se do campo indefinido do mito, da crônica e das explicações providencialistas para o campo do conhecimento científico. A partir deste ponto examinarei tendências e questões que vem marcando a historiografia, algumas das quais colocando em dúvida o próprio estatuto científico que assumiu.

Sílvia Petersen é professora do IFCH da UFRGS. 
Começarei lembrando que a história tem um papel fundamental na construção de identidades sociais. Como observa Enrique Moradiellos em El oficio de historiador, qualquer grupo humano precisa, para sua orientação e sobrevivência no presente, de uma consciência de seu passado coletivo, de sua duração como grupo, que transcenda ao passado biográfico de cada um. A experiência histórica de uma sociedade é seu único referente positivo, sua única advertência tangível para saber ao que se ater e poder conceber planos e projetos. Sem ela, o futuro seria um salto no vazio. Assim, apropiar-se do passado é, antes de mais nada, um mecanismo de auto-preservação social.

Se não está em questão a necessidade de possuir uma história, esta necessidade, no entanto, pode satisfazer-se com formas de conhecimento/ representações do passado muito diversas: mitos de criação, genealogias heróicas,ação de forças metafísicas. Também pode se expressar através de uma historiografia de clara intencionalidade propagandística: esta história "instrumento de legitimação do poder" foi a mais difundida durante a época contemporânea, em consonância com o processo de laicização geral experimentado nas sociedades industriais.

A conexão entre os conceitos de história e ciência é um fenômeno bastante recente. Só com a Ilustração, no século XVIII, começou o processo que levou a união de ambos, dando origem a um vocábulo composto: a ciência da história.

A grande revolução nesse processo em que a história vivida se transforma em conhecimento foi que, desde fins do século XIX, o relato que pretende dar contas do passado começou a diferir notavelmente de todos que o precederam: "quer ser verdadeiro e não fitício ou arbitrário; verificável materialmente e não incomprovável; causalista e imanente ao próprio campo das ações humanas e não fruto do acaso ou de forças insondáveis, racionalista e não alheio a toda lógica; crítico e não dogmático." (1). Ou seja, diferentemente das formas de história construídas desde Heródoto, a partir do século XIX o conhecimento do passado procurou assumir o modelo da racionalidade científica e em nosso século complexificou-se de forma extraordinária, até ser ele mesmo submetido à crítica do paradigma em que busca sustentação.

Na trajetória de aproximar o conhecimento histórico aos padrões da ciência daquela época, não foi pequena a influência do positivismo comtiano, ao menos no ambiente cultural latino através da chamada Escola Metódica da historiografia. Mas uma trajetória análoga, embora não recorrente a Comte, também pode ser observada no empirismo inglês e no cientificismo alemão. 
Aquela concepção de história científica da virada do século, de reconstituir o que realmente aconteceu através da completa separação entre sujeito e objeto que garantisse a objetividade do conhecimento e que tinha na narração sua expressão escrita por excelência, embora logo fosse criticada por suas insuficiências empiristas, de modo curioso mas não surpreendente prolongou-se até nossos dias, pois é a forma espontânea, de senso comum, não teoricamente mediada, de reconstruir ao passado. Como sabemos, nem só de produções acadêmicas vive o conhecimento histórico: pela própria necessidade social de sua construção e pelo fato de que qualquer um pode proclamar-se historiador (como dizia Pierre Vilar, esta é uma marca pouco protegida...), uma considerável parcela do que se designa como 'história' é resultado da intenção de historiadores amadores (ou profissionais) de descobrir, pela via da apropriação empírica, o que realmente aconteceu.

Mas voltando ao século XIX, os historiadores logo perceberam a impossibilidade radical de descobrir o passado como queriam Ranke ou Langlois e Seignobos, estes da referida Escola Metódica. A presença inevitável do sujeito no processo cognitivo desfez a ilusão do dado puro. Assim, de uma crença na rígida objetividade empirista, uma parcela dos historiadores fez um movimento oposto em direção ao subjetivismo-relativista. Através das concepções como as de Croce e Collingwood, o conhecimento histórico foi concebido como arte e reduzido a um produto do pensamento do historiador que o atualizava permanentemente. O chamado presentismo talvez seja a marca mais evidente desta postura na historiografia. (2)

Entretanto, apesar da crítica à historiografia positivista, a concepção subjetivista do conhecimento histórico não foi suficiente para que os historiadores renunciassem ao ideal da objetividade e ao horizonte da ciência.

Como se sabe, as concepções do racionalismo científico do século XIX se estenderam a outros campos do pensamento social, um dos quais particularmente viria ter profunda influência no conhecimento histórico: o marxismo.

Com Marx, pela primeira vez a idéia de uma ciência da história se distingue do modelo empirista. Marx, ao analisar o capitalismo, percebeu que não se tratava de descrever o que via e sim de construir o campo teórico, os conceitos e as categorias que permitissem descobrir as relações que efetivamente ocorreram na sociedade e que se apresentam em sua forma aparente e fenomênica. Por isto, alguns historiadores referem-se a Marx como tendo realizado a revolução copernicana no conhecimento histórico. 
Assim, ao contrário do que propunha a historiografia positivista/ empirista do século XIX, o trabalho do historiador não era a descoberta do que realmente aconteceu, mas uma construção do conhecimento do passado a partir de seus indícios, o que aponta para os inevitáveis componentes subjetivos e para a impossibilidade do historiador prescindir da interpretação. Entretanto, se o conhecimento histórico tem pretensões de explicação científica, não pode ser arbitrário. Por isso, para historiografia marxista são discussões importantes tanto o papel da mediação teórica na produção do conhecimento como a da natureza da objetividade.

Também diversamente das filosofias da história, que buscavam encontrar fora do próprio processo histórico as leis universais que o regiam, o marxismo remeteu para as práticas sociais, para o mundo dos homens, a chave da explicação da história, mas, herdeiro do modelo científico do século XIX, não esteve isento do mecanicismo, determinismo e evolucionismo linear que o caracterizou. Assim a tensão sujeito/estrutura ou voluntarismo/determinismo é constitutiva e permanente na teoria marxista da história.(3)

De qualquer forma, antes de mais nada o marxismo era uma teoria da revolução, o que dificultou seu trânsito no meio eminentemente conservador dos historiadores acadêmicos da época, de modo que só ao redor dos anos 50 é que teve uma influência visível na historiografia. Por isto, foi a Escola dos Anais que, desde 1929, passou a ser a frente "acadêmica" de combate à história dos eventos, narrativa, "positivista", à qual opunha a história-problema, mediante a formulação de algo como hipóteses de trabalho. Se nunca ficou muito claro, por suas conhecidas insuficiências teóricas, qual era exatamente o estatuto que atribuía ao conhecimento histórico, de qualquer forma ele oscilou ciência dos homens no tempo e conhecimento cientificamente elaborado. Em oposição à historiografia anterior, para quem os fatos históricos eram os eventos políticos produzidos por personagens renomados, a Escola dos Anais, assumindo a idéia da história total e de que tudo é história, estendeu extraordinariamente as fronteiras deste conhecimento e, em conseqüência, ampliou a noção de fonte histórica e promoveu a aproximação interdisciplinar.

Por uma dupla lógica, a do conhecimento científico e a da extensão do objeto, a idéia de história total, estrutural, foi uma característica dos historiadores dos Anais pelo menos até o final dos anos 60 .

Se comparamos com os dezenove séculos anteriores,- para não ir mais longe- é inegável a extraordinária transformação que o conhecimento histórico experimentou em algumas décadas pela via do positivismo, do marxismo ou dos Anais, para ficar apenas em três campos significativos. 
No caso da influência marxista e da Escola dos Anais no conhecimento histórico, pode ser percebida, com as devidas mediações, a herança do paradigma científico moderno. Assim, a totalidade dialética marxista e história total dos Anais apontam, por vias diferentes, para o princípio macroexplicativo e sistêmico do conhecimento científico. A interdisciplinariedade da Escola dos Anais e a idéia marxista de que não existe senão uma ciência, a História, remetem ao princípio da unidade do conhecimento. A história-problema dos Anais tem um estatuto teórico muito inferior à preocupação marxista da construção do objeto teórico, mas em ambas se advertem estágios diferenciados do princípio científico da necessidade de ultrapassar a visão aparente, fenomênica, com que os objetos se apresentam ao conhecimento. No caso da influência marxista, ela coloca para o conhecimento histórico a questão da mediação teórica entre o sujeito que conhece e o objeto de investigação; isto não acontece nos Anais, onde a cientificidade da investigação se limita à aplicação de métodos em geral importados de disciplinas "científicas" vizinhas como a geografia, a economia e a antropologia. Em particular, a historiografia de influência marxista assumiu o horizonte científico da busca da explicação verdadeira, o que traz para o debate historiográfico as questões da objetividade e subjetividade, via de regra sob a forma das relações entre ciência e ideologia e dos complicados problemas da verificação dos resultados.

Nos anos 70, tomando este marco de modo flexível, o conhecimento histórico passa a sofrer as influências disto que muitos chamam "crise da modernidade", ou seja, a consciência do esgotamento da razão e de sua forma de conhecer o mundo, a ciência, tanto por sua incapacidade de abrir as prometidas vias de progresso humano, como de prever o que se avizinhava. O tema tem sido exaustivamente discutido, de modo que só quero sublinhar que esta crise põe em questão o modelo de conhecimento científico assumido pela historiografia.

Das teorias da história e as correspondentes historiografias que partiram deste paradigma, a marxista foi a mais atingida: no caso da historiografia de orientação positivista, suas insuficiências há muito tinham sido constatadas e a Escola dos Anais, por não ter assumido um perfil teórico mais rigoroso, também não teve que enfrentar diretamente a critica paradigmática. A historiografia marxista foi a mais atingida, entre outras razões, por ter assumido a vertente mecanicista, determinista e evolucionista do pensamento científico, pouco incorporando a concepção dialética ou a advertência de Marx de que os homens fazem a história mas em circunstâncias que não são por eles escolhidas ou seja, ignorando freqüentemente a tensão entre sujeito e estrutura, crucial para pensar qualquer sociedade. 
Também não é irrelevante neste processo e sem que constitua nenhuma contradição com o que foi dito, o viés teoricista,- e especialmente me refiro aqui à obra de Althusser- com que o marxismo foi apropriado por muitos historiadores, provavelmente em razão de sua pouca tradição de uso do instrumental teórico no trabalho de investigação. Quando, em lugar de ser um referencial analítico, o pensamento teórico obstaculiza o desenvolvimento desta "capacidade de reconhecimento" que lhe é própria, ele impede que amadureçam visões possíveis desde o interior de uma situação histórica, circunscrevendo-se a limites fixados pela própria estrutura teórica. Este tipo de deformação, que em todo o caso os historiadores nunca resolveram completamente, deve ter contribuído para frustrar as expectativas sobre as virtualidades da teoria marxista para a explicação histórica.

Resumindo, se vários eixos da forma de conhecer instituída pelo paradigma científico da modernidade são abalados, abre-se espaço para que outras linhas de pensamento venham à tona. Vale a pena indicar algumas delas, pois constituem basicamente o conteúdo da discussão historiográfica contemporânea.

Assim, a crítica à razão abre espaço para que aspectos não-racionais, inconscientes, subjetivos, sejam incorporados ao conhecimento histórico; também há uma tendência de retorno ao senso comum, contra o qual a ciência se constituíra.

Por outro lado, a visão macrológica, a totalidade dialética do marxismo ou a história total dos Anais, é enfrentada pela fragmentação do objeto, a história em migalhas de que fala François Dosse, tendência provavelmente fortalecida pela expansão espetacular de seu campo de estudos nos últimos trinta anos. Também não é mais a estrutura, mas a ação do sujeito o centro do interesse do historiador. A descontinuidade toma o lugar da concepção de evolução linear. Quanto aos critérios científicos da validade do conhecimento, -a objetividade e veracidade da explicação seus fundamentos são abalados pelo questionamento da idéia de representação, pilar da reflexão científica moderna. O chamado "giro lingüístico" faz o discurso histórico deslizar para a estética e, como simples gênero literário, perde a pretensão de ser também um discurso verdadeiro, diluindo as fronteiras com a ficção.

Neste debate parecem predominar as discussões sobre o que se chama "explicação" em história, ou seja, sobre a natureza do discurso histórico. Mas também estão na pauta as relações entre razão e imaginação, entre verdade e ficção, entre narração e argumentação. Em suma, o debate visa principalmente a maneira pela qual o historiador constrói e apresenta a "sua" história, o caráter científico ou não daquilo que os historiadores 
escrevem.

Essas questões envolvem um conjunto complexo de desdobramentos e não são assumidas igualmente pelos historiadores. Assim, é muito diferente a posição dos historiadores marxistas britânicos e dos historiadores da nova história francesa (também conhecida como a terceira geração dos Anais), para dar dois exemplos significativos.

Um parêntesis para dizer que minha resumida exposição deixa de lado inúmeros outros caminhos, igualmente inscritos nesta riquíssima discussão historiográfica do final do século, como os trabalhos de M. Foucault, a micro-história italiana (E. GRENDI, C. PONI, C. GINZBURG, G. LEVI) e a nova história cultural, (R. CHARTIER, L. HUNT), para citar alguns dos mais importantes.

O grupo dos historiadores marxistas britânicos considera que a solução para a crise do conhecimento histórico não pode se basear na negação radical do anterior e na sua apressada substituição por achados pontuais, que só respondem a uma pequena parte dos problemas dos historiadores. Ao contrário, ela exige um esforço para recuperar, ao mesmo tempo, alguns fundamentos teórico-metodológicos sólidos e, sobretudo, o contato com os problemas reais dos homens e mulheres de nosso tempo, dos quais as tendências historiográficas pós-modernas se distanciaram.

Apesar das diferenças visíveis entre eles, não abandonam o princípio racional-explicativo do conhecimento científico, nem a especificidade do discurso histórico, comprometido com a representação de um passado com existência real, ao mesmo tempo em que rompem tanto com as leituras estruturalistas-economicistas como teoricistas do marxismo, recuperando o espaço do sujeito e da cultura e os referentes materiais das categorias. A esses historiadores se devem não só importantes contribuições individuais aos estudos históricos senão que, como grupo fizeram uma contribuição coletiva tanto à historiografia como à teoria social, além de seu engajamento no sentido da formação de uma consciência histórica democrática e socialista.(4)

Quanto à Nova História,entendida aqui como a terceira geração dos Anais, é muito difícil traçar seu perfil, sendo talvez exatamente a fragmentação o seu traço comum. Muitos dos historiadores que costumam ser identificados com ela são representativos das transformações ocorridas no conhecimento histórico quanto à sua pretensão científica, embora não se alinhem uniformemente diante dessas questões. Produzem trabalhos extremamente interessantes, mas que não necessariamente constituem indicações para outros historiadores no sentido da continuidade e aprofundamento de uma problemática, pois não estando em seu horizonte o desenvolvi- 
mento da reflexão teórica, transformam-se em estudos pontuais, experiências de investigação quase intransferíveis apesar dos inúmeros trabalhos que inspiraram. A pluralidade interpretativa, sem relações estreitas com seu objeto real, também deriva com facilidade ao relativismo. É possível que esses historiadores estejam cruzando a tênue fronteira a partir da qual o conhecimento histórico deixa de sê-lo. De qualquer forma, trouxeram muito combustível às discussões historiográficas nos últimos anos, arregimentando ao seu redor admiradores incondicionais e críticos implacáveis.

Há um ângulo deste tema da crítica ao paradigma moderno que quero comentar particularmente. Quando alguns historiadores criticam o modelo da ciência que o conhecimento histórico procurou assumir, sua crítica refere-se a uma ciência que só existe para quem ignora princípios básicos de epistemologia, carecendo muitas vezes de fundamento até para definir a que tipo de ciência se refere. Enquanto muitos historiadores continuaram obcecados pela concepção mecanicista, a ciência já havia descoberto que o universo era muito mais complexo do pensava Newton, que as leis físicas fundamentais expressam hoje possibilidades e não certezas. Enquanto o historiador se esforçava para ser mimeticamente científico, ao ponto de renunciar ao que era específico em seu trabalho, -a ação dos sujeitos-, os cientistas da natureza abandonavam a tentação de uma explicação do mundo baseada no determinismo de algumas leis, colocando em seu lugar a centralidade de relações não-lineares, muito mais abundantes na natureza e na vida, chegando a assumir a historicidade como uma característica importante da ciência.

É certo que a Nova História, mais ainda que as gerações anteriores dos Anais, não tem no seu horizonte de preocupações a reflexão teórico-epistemológica. Mas muitas vezes sua crítica a alguns princípios científicos assumidos pelo conhecimento histórico, como a busca da objetividade, é de um simplismo inaceitável, sobretudo se observamos que nela incorrem historiadores eruditos e originais. Esta objetividade, considerada impossível para o conhecimento histórico, é um conceito tão pobre, procede de noções tão vagas, que seria igualmente impossível reconhece-la nas próprias ciências exatas. Dentro desta cadeia de simplificações, não tendo compromissos com a realidade como referência objetiva, também é fácil ao historiador concluir que o conhecimento histórico não se distingue da narrativa ficcional ou é o sonho do historiador materializado em texto. Se é assim com profissionais de expressão, pode-se imaginar os vieses e simplificações que outros, sem o destaque daqueles, realizam ao assumir as críticas à razão e à ciência. 
Por isso, não me parece absurdo pensar que a apropriação de uma visão "pós-moderna", independente das conseqüências que possa trazer ao conhecimento histórico, tem como uma de suas causas a tradicional superficialidade teórica do historiador, a começar pelo próprio desconhecimento da história das teorias da história. Creio que este motivo também concorre para atitudes pragmáticas por parte de alguns historiadores que, sem reflexões mais conseqüentes, limitaram-se a se ajustar às novas tendências, vividas então como "modas" (onde a pressão das editoras não é uma variável irrelevante), para sobreviver em um meio acadêmico cada vez mais competitivo.

Mas por outro lado pode-se observar, e agora positivamente, que a necessidade de tomar posição e dar respostas às questões que abalam certezas antes inquestionadas, tem provocado o salutar efeito de que os historiadores, como nunca, estejam preocupados e envolvidos com os pressupostos teóricos de seu próprio trabalho. Um indicador desta tendência é quando verificamos, tomando apenas os anos de 1997 e 1998, a publicação de numerosas obras coletivas ou artigos das mais diversas procedências, brasileiros inclusive, que desde diferentes ângulos vem tratando de refletir com profundidade e originalidade sobre essas questões ou de diagnosticar, digamos, "o estado da arte".

De qualquer forma, os historiadores parecem estar de acordo em que hoje se conhece o passado melhor do que antes, embora não se saiba ainda exatamente para onde a crise levará conhecimento histórico.

Este momento tão fértil da prática historiográfica leva a um paradoxo muito bem sintetizado por um historiador norte-americano, cujas palavras cito:

“-Nunca no passado a escrita da história foi tão abundante como hoje, nunca ela espalhou uma massa tão grande e sufocante de produções estultas e triviais, fruto de mentes acanhadas, engajadas na ocupação congênita de escrever mal sobre temas insignificantes, aos quais dispensaram pouca ou nenhuma reflexão e pelos quais na verdade sentem pouco interesse.

-Nunca no passado houve historiadores escrevendo história de modo tão competente, vigoroso e refletido como hoje, penetrando em domínios antes negligenciados ou deixados obscuros, oferecendo efetivamente suporte para fazer emergir dos registros do passado questões que foram completamente inacessíveis a seus antecessores, tratando os problemas que eles enfrentaram com uma universalidade, rigor e sofisticação de método nunca antes desenvolvidos entre os praticantes do trabalho historiográfico." (5)

Desta constatação poderíamos derivar um elenco de questões 
concernentes ao trabalho historiográfico na atualidade e vou apontar algumas delas, numa seleção que, em todo o caso, é muito incompleta.

1-Assim, é certo que vivemos uma notável extensão quanto à temas e problemas do conhecimento histórico. Novos objetos são trazidos para o âmbito da pesquisa e velhos objetos são retomados à luz de novas perguntas e perspectivas analíticas. No primeiro caso, vale lembrar como têm sido investigadas as múltiplas dimensões da vida privada, a importância concedida à vida cotidiana, os espaços do sujeito, suas práticas e representações. No segundo caso, também novas perspectivas analíticas tem sido propostas pelos historiadores marxistas britânicos, pela micro-história e pela nova história cultural, para citar alguns caminhos, não necessariamente excludentes. Por outro lado, temas aparentemente esgotados são retomados à luz dessas novas perspectivas analíticas: é o caso no Brasil, por exemplo, dos temas da República, da escravidão, do movimento operário, dos descobrimentos, das biografias, etc. Enfim, a lista é grande.

2- Esta avaliação positiva não significa, no entanto, desconhecer que em muitos casos a extensão temática não é acompanhada por incursões teóricas capazes de manter a vocação explicativa do conhecimento histórico e esses trabalhos acabam recaindo no mesmo viés empirista já tão longamente criticado pela própria historiografia.

Da mesma forma, a virtualidade analítica das novas referências teóricas (no caso delas existirem) muitas vezes sucumbe ao uso vulgar que sofrem por parte de alguns historiadores, mais preocupados com seu próprio "aggiornamento" do que com a reflexão historiográfica propriamente dita. Assim, tal como em outros momentos aconteceu com o positivismo comtiano (a chamada historiografia positivista distanciou-se de Comte) ou com categorias analíticas do marxismo, (que perderam sua historicidade) hoje, por exemplo, não é difícil encontrar no trabalho historiográfico o conceito de vida cotidiana reduzido ao limite da "rotina diária", as noções foucaultianas de disciplina e poder deslocadas do contexto teórico e do sentido que lhes conferiu o autor e o uso vulgar da categoria representação, esvaziada dos serviços teóricos específicos apontados por Chartier e transformada em uma designação tão genérica que não possui qualquer valor analítico. Enfim, apesar de uma imensa riqueza de possibilidades que a reflexão teórico-metodológica oferece hoje aos historiadores, em muitos casos elas são pasteurizadas e reduzidas a algumas "palavras de ordem" timoneiras, que vão simplificando o que é complexo, reduzindo o novo a modismo. Como observa Emilia Viotti da Costa, alguns desses conceitos "tornaram-se expressões comuns no jargão do historiador, embora freqüentemente apenas como parte de seu vocabulário e não como parte de 
sua teoria." (6)

Outro viés importante, também percebido agudamente pela mesma Autora, refere-se à polarização que se observa na produção do conhecimento histórico. Houve um deslocamento da ênfase nas abordagens macro-orientadas, estruturais, para a ênfase no subjetivo, no ficcional, no micro-centrado. Este desvio não produziu um enriquecimento do princípio dialético básico de que os homens fazem a história, mas não em condições de sua própria escolha. O desvio de uma posição teórica para outra foi apenas uma inversão; nós passamos de um reducionismo para outro. Ambas são igualmente insatisfatórias, pois não dão conta da complexidade da vida social. No entanto o saldo positivo é que, graças a tal inversão, pode ser possível hoje tentarmos uma nova síntese entre estrutura e sujeito.

3- Outra tendência visível do conhecimento histórico atual é a ampliação das fronteiras, não só pela referida extensão dos temas e problemas, como pela progressiva historicização de outras disciplinas, como a antropologia, a sociologia, a psicologia, etc.

4- A mesma razão tem levado a que os historiadores se lancem com freqüência em percursos interdisciplinares. Esta constatação merece comentários, pois a atividade interdisciplinar tem sido muitas vezes uma panacéia para suprir lacunas teóricas que os historiadores não tem preenchido e que necessitam para dar conta de alguns dos objetos que incorporam à sua análise. Além do fato de que, no meu entender, a atividade interdisciplinar como tal necessite ser urgentemente discutida nas ciências humanas, no caso particular dos historiadores eles muitas vezes se apropriam de forma demasiado superficial de campos de conhecimento tão complexos e problemáticos como a história, resultando daí leituras enviesadas, que não prestam serviços analíticos ao conhecimento histórico. Só para dar um exemplo, lembro as freqüentes referências à descrição densa em trabalhos de história, procedimento metodológico muito qualificado na antropologia e que naqueles trabalhos resume-se em oferecer numerosos detalhes sobre uma situação em estudo. Não estou criticando as virtualidades do trabalho inter ou transdisciplinar; o que quero destacar é o modo inconseqüente com que alguns historiadores usam conceitos e métodos que não dominam e que transmitem a outros, que os conhecem menos ainda, sob a forma de conexões absurdas passivamente aceitas, produzindo assim uma pirotecnia verbal esvaziada de conteúdo.

5- Outra característica importante da historiografia contemporânea é que ela se origina como nunca do trabalho do historiador profissional, daquele que teve uma formação acadêmica, experiência em pesquisa e interlocução com seus pares em seminários, congressos, etc. No caso brasileiro, a cria- 
ção dos Cursos de Pós-Graduação em História (hoje cerca de trinta) tem um peso significativo nesta qualificação, responsável pelo fato de que o profissional de história vem ampliando seu campo de trabalho não só no ensino como na pesquisa e no gerenciamento do patrimônio histórico. 6- Também atualmente o conhecimento histórico se caracteriza por ser um gênero de muito sucesso junto ao público leitor; se isso é um ganho inequívoco, por outro a esfera da divulgação cultural detém em grande parte o poder de escolha e, como em outros ramos, cria modas, que por sua vez incidem na produção historiográfica, determinando em boa parte o que está sendo produzido.

7- Por último, numa caracterização que deveria ser muito mais completa, quero falar nos efeitos disto que, para acompanhar uma expressão consagrada, estou chamando "giro lingüístico" e que talvez seja a questão mais importante na discussão atual sobre o conhecimento histórico, especialmente pela quantidade de desdobramentos que possibilita e pela radicalidade com que mergulha o conhecimento histórico no domínio literário e estético. Essa discussão, que não é um falso problema, atraiu muitos historiadores, que se apropriaram de ângulos particulares e diferentes da mesma, de modo que o "giro" tornou-se mais um "zigue-zague".

De qualquer forma, o giro lingüístico é objeto de uma igualmente importante crítica por parte dos historiadores no sentido de que ignora características e requisitos que são centrais para o conhecimento histórico. Um deles é a diferença que a história estabelece entre fato e ficção, para o que a perspectiva estética não oferece solução.

Como observa Eric Hobsbawm, diferentemente do trabalho da literatura, o conhecimento histórico não se refere a um mundo imaginário ou inventado. Ele se apresenta, em grande medida, constituído de fatos e afirmações verdadeiras ou prováveis sobre o passado. Cada reflexão histórica que se escreve pode conter muitas afirmações falsas ou errôneas e propor interpretações contestáveis quando se deixa de fora o horizonte da veracidade, por difícil que seja alcançá-lo. Por isso, é também uma outra característica intrínseca da historiografia a necessidade de justificar suas afirmações. Os historiadores sabem que poderão ser chamados para demonstrar a base da veracidade, adequação e realismo das interpretações e afirmações que fizeram. Sua forma de escrever, por isso, não é qualquer forma, mas aquela apta a incorporar muitas justificativas sobre os juízos que emitem, as opiniões que expressam e as descrições e análises que apresentam no tratamento da matéria histórica. Mesmo a mais modesta narrativa histórica é incapaz de dispensar a necessidade de justificativa se quiser ser aceita por leitores críticos. 
A estetização da historiografia, que alguns autores concebem como a maior criação pós-moderna, inevitavelmente resulta em uma trivialização da história através da derrubada das características de conhecimento que, ao mesmo tempo, definem a história como uma forma de pensamento e lhe dão seu significado. Enfim, pode-se escrever excelentes livros sob o passado, mas isto não significa que sejam história. (7)

Em trabalhos recentes, Eric Hobsbawm e Francisco Falcon com palavras diferentes expressam esta mesma concepção sobre o que constitui a história e o historiador, e com as quais estou de acordo.

Hobsbawm argumenta ser essencial que os historiadores defendam o fundamento de sua disciplina: a supremacia da evidência.

"Se seus textos são ficções, como são em certo sentido, constituindo-se de composições literárias, a matéria prima dessas ficções são fatos verificáveis.(...) O fato de que os fornos nazistas tenham existido ou não pode ser estabelecido por meio de evidências. Uma vez que isto foi assim estabelecido, os que negam sua existência não estão escrevendo história, quaisquer que sejam suas técnicas narrativas.(...) A responsabilidade pública do historiador repousa acima de tudo no fato de que os historiadores são produtores básicos da matéria prima que é convertida em propaganda e mitologia.(...) A história ruim não é inofensiva. Ela é perigosa. As frases digitadas em teclados aparentemente inócuos podem ser sentenças de morte. $(. . .)^{\prime \prime} .(8)$

Falcon reconhece que se tratam de constatações importantes a percepção da pluralidade de passados que o historiador recompõe e dos elementos de ficção que o discurso histórico incorpora. Mas acrescenta:

"O decisivo, porém, é que não se perca de vista a capacidade deste discurso de dizer algo verdadeiro a respeito de uma realidade passada que constitui seu referente extra-discursivo. Logo, por mais que se pretenda o inverso, o historiador não é nem pode ser um autor de ficção, pois não é livre para inventar, imaginar e interpretar: o exercício de suas faculdades criativas está limitado pelas evidências documentais disponíveis no seu próprio tempo e lugar. É a partir de protocolos de verdade que se identificam, em derradeira instância, a história e o historiador como tais". (9)

Entretanto, isto não significa desconhecer o que também observa Martin Jay:

“(...) defender um momento racional em nosso método não equivale a negar a importância do recente giro da filosofia em direção às questões lingüísticas. Assim como a alternativa de ver a linguagem como perfeitamente transparente ou como to- 
talmente opaca está colocada com demasiada rigidez, também a oposição entre uma história intelectual lingiiísticamente informada e outra inspirada em conceitos tradicionais (ou, no caso de Habermas, não tradicionais) da racionalidade é extrema até um limite desnecessário. É impossível dizer se os horizontes podem fundir-se perfeitamente ou se devem permanecer para sempre em uma interação suplementar. Mas sem um certo jogo dialógico entre eles, nossa leitura do passado seguirá sendo ou anacrônica, no sentido de ser indiferente às correntes filosóficas mais vivas de nossa época, ou, o que é pior, incapaz de proporcionar uma perspectiva crítica do passado e do presente em nome de um futuro mais atrativo." (10)

Bem, todas estas numerosas questões que perpassam hoje a historiografia e que há cem anos Ranke ou Langlois e Seignobos jamais teriam imaginado, demonstram que ser historiador neste começo de século pode ter inúmeras dificuldades, dentre elas a aviltada remuneração, mas certamente não é uma trajetória intelectual irrelevante ou aborrecida.

\section{BIBLIOGRAFIA}

1-MORADIELLOS, Enrique. El oficio de historiador. Madrid, Siglo XXI, 1994. p. 15

2-SCHAFF, Adam. História e verdade. São Paulo, Martins Fontes, 1973.

3-GOULDNER, Alvin. Los dos marxismos. Contradicciones y anomalías en el desarrollo de la teoria. Madrid, Alianza, 1983.

4-KAYE, Harvey. Los historiadores marxistas britanicos. Zaragoza, Prensas Universitárias. 1989.

5-HEXTER, J.H. Some American Observations. Journal of Contemporary History n. 2, p.5-6. 1967.

6- COSTA, Emilia Viotti da. Novos públicos, novas políticas, novas histórias: do reducionismo econômico ao reducionismo cultural; em busca da dialética. Anos 90. PPG em História da UFRGS. n.10, p.722, dez. 1998..

7- ZAGORIN, Perez. Historiography and Postmodernism: Reconsiderations. History and Theory. Wesleyan University, v.29, n. 3, October 1990

8-HOBSBAWM, Eric. Não basta a história de identidade. IN: Sobre História. São Paulo, Cia das Letras, 1998. p. 286-7; 290; 292. 
9-FALCON, Francisco. Apresentação. IN: BOUTIER, Jean e JULIA, Dominique. Passados recompostos. Campos e canteiros da história. Rio de Janeiro, Editora da UFRJ/ Editora da FGV, 1998. p. 18.

10- JAY, Martin. Deberia da historia intelectual tomar un giro lingüístico? Reflexiones sobre el debate Habermas-Gadamer. IN: Socialismo "finde-siècle" y otros ensayos. Buenos Aires, Nueva Visión, 1990. p. 49. 